\title{
Influence of Galvanized Coatings on Abrasion Circle Friction Stir Spot Welding Aluminium to Steel for Automotive Applications
}

DOI:

10.4028/www.scientific.net/MSF.783-786.1741

\section{Document Version}

Accepted author manuscript

Link to publication record in Manchester Research Explorer

Citation for published version (APA):

Chen, Y. C., Liu, S. F., \& Prangnell, P. (2014). Influence of Galvanized Coatings on Abrasion Circle Friction Stir Spot Welding Aluminium to Steel for Automotive Applications. Materials Science Forum, 783, 1741-1746. https://doi.org/10.4028/www.scientific.net/MSF.783-786.1741

\section{Published in:}

Materials Science Forum

\section{Citing this paper}

Please note that where the full-text provided on Manchester Research Explorer is the Author Accepted Manuscript or Proof version this may differ from the final Published version. If citing, it is advised that you check and use the publisher's definitive version.

\section{General rights}

Copyright and moral rights for the publications made accessible in the Research Explorer are retained by the authors and/or other copyright owners and it is a condition of accessing publications that users recognise and abide by the legal requirements associated with these rights.

\section{Takedown policy}

If you believe that this document breaches copyright please refer to the University of Manchester's Takedown Procedures [http://man.ac.uk/04Y6Bo] or contact uml.scholarlycommunications@manchester.ac.uk providing relevant details, so we can investigate your claim.

\section{OPEN ACCESS}




\title{
Influence of Galvanized Coatings on Abrasion Circle Friction Stir Spot Welding Aluminium to Steel for Automotive Applications
}

\author{
Ying-Chun Chen ${ }^{a}$, Si-Fang Liu ${ }^{b}$ and Phil Prangnell ${ }^{c}$ \\ School of Materials, Univ. of Manchester, Manchester M13 9PL, UK \\ aYingchun.Chen@manchester.ac.uk, bsifangliu@hotmail.com, philip.prangnell@manchester.ac.uk
}

Keywords: Friction stir welding; Aluminium alloys; Zinc-coated Steel; Mechanical properties; Microstructure

\begin{abstract}
It has previously been shown that dissimilar Al-alloy and un-coated steel automotive sheets can be successfully welded with a cycle time of less $<1 \mathrm{~s}$ using a novel solid state joining approach; Abrasion Circle Friction Stir Spot Welding (ABC-FSSW). The ABC-FSSW technique provides an effective strategy for exposing a larger clean steel surface during welding than conventional FSSW, allowing high failure energy joints to be produced. In this study the influence of different steel zinc coatings on the viability of the ABC-FSSW process has been systematically investigated - focusing on the effect on the process window, weld temperatures, and joint performance. The effect of a galvanised coating on the weld formation, zinc dispersal in the joint, and interface intermetallic reaction behaviour are discussed.
\end{abstract}

\section{Introduction}

The need for weight saving in the automotive industry has led to increasing demand for multimaterial designs involving high performance Al-alloys and $\mathrm{Zn}$ coated steels. The development of reliable techniques for joining Al to galvanized steel automotive sheet has thus become a high priority (e.g. [1,2]). Resistance spot welding (RSW) is currently the dominant method used for joining steel car bodies [1-3], but is difficult to apply to dissimilar metal joints because of the rapid intermetallic reactions that can occur [3,4]. Compared to RSW, friction stir spot welding (FSSW) is a relatively new technology that is attractive for joining multi-material structures [1-3] because it reduces intermetallic compound (IMC) formation by avoiding the liquid phase. To date, four main approaches have been examined for FSSW of aluminium to steel; i) FSSW with a pin tool, ii) FSSW with a pinless tool, iii) friction bit joining (FBJ), and more recently by the current authors; iv) Abrasion Circle Friction Spot Welding (ABC-FSSW) [1-3].

In FSSW of Al to steel using a pin tool the metallurgically bonded area is generally only a small region at the periphery of the pin, because of the limited area of the steel sheet surface that is deformed and the exit hole left by the probe $[2,3]$. In comparison, using a pinless tool can maximize the joint area by eliminating the exit hole [3]. However, in this case a sticking condition occurs across the top and bottom sheet interface and there is no surface cleaning effect. As a result, it is difficult to obtain a strong bond. The FBJ process uses a consumable steel bit that penetrates through the aluminium top sheet and is friction welded to the steel bottom sheet and thus largely forms a joint by mechanical locking [2]. More recently it has been demonstrated that ABC-FSSW can successfully produce high performance joints between Al/Steel automotive sheet, with a wide process window and within industrially relevant welding times $(<1 \mathrm{~s})$ [1]. More detail about this approach can be found in ref. [1].

It has in general been found to be more difficult to apply FSSW techniques to dissimilar joining $\mathrm{Zn}$ coated steels [2,3]. This is because the $\mathrm{Zn}$ coat reduces the friction between the top and bottom sheet and readily melts through a low temperature eutectic reaction with $\mathrm{Al}$, which can cause tool sticking and weld defects. The objective of the current study was thus to investigate if the new ABC-FSSW process could be used to successfully weld Al alloys to zinc-coated steels within a one second cycle time, as desired by industry. The influence of the different types of coating (hot dipped 
galvanized and galvanized-annealed) on the process window, joint performance, weld formation, and interface reaction behaviour are discussed.

\section{Experimental}

An AA6111-T4 Al- alloy was joined to three grades of low carbon automotive steel: un-coated (DC04), hot dipped galvanized (DX54-Z) and galvannealed (DX53-ZF), all as $1 \mathrm{~mm}$ thick sheets. The steel compositions (shown in ref. [3]) were not identical, but were as similar as could be obtained with different zinc coatings. The sheets were cut into 100 by $25 \mathrm{~mm}$ rectangles and lapwelded, following the ABC-FSSW procedure outlined in ref. [1]. The weld was located at the centre of a $25 \mathrm{~mm}$ overlap with the $\mathrm{Al}$ sheet on top. The tool had an $11 \mathrm{~mm}$ diameter shoulder, and a tapered $3 \mathrm{~mm}$ diameter WC $1 \mathrm{~mm}$ long probe. The radius of the probe's orbital path was $2.5 \mathrm{~mm}$, which produced an $8 \mathrm{~mm}$ diameter swept area on the steel sheet surface. In the results presented the translation speed was fixed at $1000 \mathrm{~mm} / \mathrm{min}$, giving a welding time of $1 \mathrm{~s}$, and a constant shoulder plunge depth of $0.1 \mathrm{~mm}$ was used. The rotation rate of the tool was varied in the range of 800 $2000 \mathrm{rpm}$, to change the energy input to the welding process. The mechanical properties of the joints were measured by lap-shear tensile testing (crosshead speed of $1 \mathrm{~mm} / \mathrm{min}$ ) as soon as possible after welding to avoid natural ageing. The integrated area under the load-displacement curves was used to give a relative comparison of the fracture energy.

The joints were sectioned across their centre for metallographic analysis by optical and scanning electron microscopy (SEM). Samples for transmission electron microscopy (TEM) were removed from the joint interface using a Quanta 3D focused ion beam (FIB) milling system and examined in a Tecnai F30 microscope, equipped with energy dispersive X-ray spectroscopy (EDS). The thermal histories in the weld zone were measured with embedded sacrificial thermocouples inserted as close as possible to the edge of the swept area at the joint interface.

\section{Results and Discussion}

Zinc Coatings. SEM images of the top surfaces and cross sections of the galvanised steel sheets used are presented in Fig. 1a. The phases present in the zinc coatings were confirmed by $\mathrm{x}$-ray diffraction. DX54-Z is a hot-dip galvanized zinc steel with a coating that consists of a low melting point, nearly pure zinc ( $\eta$-phase) containing $\sim 0.15 \% \mathrm{Al}$ and some iron in solid solution [4]. However, there is a very thin $(200 \mathrm{~nm}) \mathrm{Fe}_{2} \mathrm{Al}(\mathrm{Zn})_{5}$ inhibition layer at the interface between the coating and steel substrate, which acts as a diffusion barrier to prevent any Fe-Zn intermetallic formation [4]. The hot dipped galvanized coating is relatively soft, although the pure zinc exhibits a high degree of galvanic protection [4]. In comparison, the galvannealed DX53ZF steel coating contains a series of high melting point $\mathrm{Fe}-\mathrm{Zn}$ intermetallic phases, which occur in order from top to bottom as; $\zeta\left(\mathrm{FeZn}_{13}\right), \delta\left(\mathrm{FeZn}_{10}\right)$, and $\Gamma\left(\mathrm{Fe}_{3} \mathrm{Zn}_{10}\right)+\Gamma_{1}\left(\mathrm{Fe}_{5} \mathrm{Zn}_{21}\right)$ [4]. This coating is obtained by using an aluminium free bath and exposing the galvanized steel to an annealing temperature around $500{ }^{\circ} \mathrm{C}$, to ensure full inter-diffusion with the substrate [4]. The annealing treatment results in a hard IMC coating, which offers improved adhesion for painting [4]. The coating mainly contains $\zeta$ and $\delta$ phases with a thin layer of $\Gamma\left(\mathrm{Fe} 3 \mathrm{Zn}_{10}\right)+\Gamma_{1}\left(\mathrm{Fe}_{5} \mathrm{Zn}_{21}\right)$ at the steel interface [4]. The crystalline nature of the FeZn $\mathrm{n}_{13}$ intermetallic compound can be seen from the top surface. The un-coated DC04 steel surface is also shown in Fig.1 a for comparison.

Process windows. It can be seen from Fig.1b that with un-coated steel there is a large parameter range where sound joints can be produced by ABC-FSSW. However, when attempts were made to weld the Al-alloy to a soft zinc coated steel (AA6111/ DX54-Z) the results were extremely poor. No conditions were found where sound welds could be produced, even though a wide parameter range was explored (Fig.1b). Welding always resulted in the top sheet cracking and often a disk of Al was pulled out on withdrawal of the FSSW tool. This suggests that the Al under the tool was 
sliding at the interface between the two sheets, leading to shear cracking, and often became bonded to the tool. This behaviour can be explained by the low shear strength of the $\mathrm{Zn}$ coating, leading to low sliding resistance even under sticking conditions, and liquation occurring at the joint interface during welding [3], which severely affects the weldability (see below, Fig. 3).

More success was obtained with the Al to hard $\mathrm{Zn}$ galvannealed steel combination (AA6111/ DX53-ZF), although the process window was narrower than with the un-coated steel. This difference in behaviour between the two $\mathrm{Zn}$ coatings occurs because the galvannealed coating only had a thin $\sim<0.2 \mu \mathrm{m}$ thick $\eta$-phase $\mathrm{Zn}$ top layer, above the hard higher melting point Fe- $\mathrm{Zn}$ intermetallic layers [4], and this produces an insignificant level of liquid phase during welding. As will be seen below, the brittle galvannealed coating was removed by the pin during welding and incorporated into the joint as fine $\mathrm{Fe}-\mathrm{Zn}$ intermetallic particles. A high interface sliding resistance was thus more readily obtained between the top and bottom sheets, which is essential to prevent tearing as the tool translates.

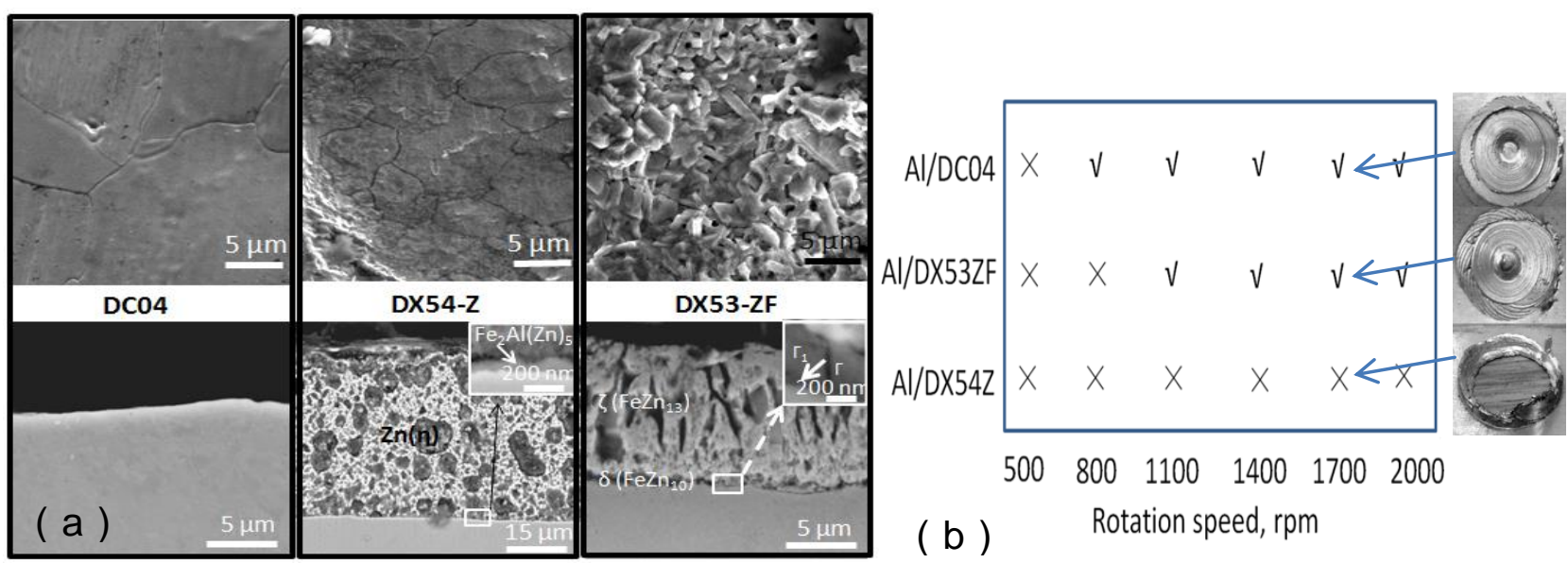

Fig. 1 (a) SEM images of the surface and cross section views of the different galvanized steel sheets prior to welding: left to right- DC04, DX54-Z, DX53-ZF; (b) the processes windows for the different $\mathrm{Al} /$ Steel combinations and typical weld appearance.

Joint strengths and failure modes. The effect of rotation speed on the maximum failure load and energy are compared for the AA6111/DC04 and AA6111/DX53-ZF defect-free welds in Fig. 2a. Typical failure modes and fracture paths are shown in Fig.2b. Estimates of the welding energy, obtained from integration of the machine torque, indicated that it was slightly higher for the uncoated steel welds (increasing from 1.4 to $1.6 \mathrm{~kJ}$ and 1.2 to $1.4 \mathrm{~kJ}$ for the AA6111/DC04 and AA6111/ DX53-ZF welds, respectively on raising the rotation speed from 1100 to $2000 \mathrm{rpm}$ ).

Although FSSW trials were preformed across a wide range of rotation rate, the welds' mechanical performance showed remarkably consistent results. In the as-welded condition, all the joints failed by nugget pull-out. The maximum failure loads were slightly higher for the galvannealed steel; being 3.2 and $3.4 \mathrm{kN}$, for the Al/DC04 and Al/ DX53-ZF weld combinations, respectively. With the Al/DC04 welds, the failure energy reached about $6 \mathrm{kN} . \mathrm{mm}$. In comparison, the Al/DX53-ZF welds exhibited maximum failure energies of $8 \mathrm{kN} . \mathrm{mm}$. It should be noted that these failure energies are substantially greater than normally observed in conventional FSSWs between $\mathrm{Al}$ and steel sheets of the same thickness, where values reported are typically in the range of 1-2 kN.mm for un-coated steel joints [3].

From the sections through partially failed samples, it can be seen that the fracture path initiated at the edge of the welded area where there is a stress concentration and then propagated from this location following the steel hook's surface to tear through to the Al top sheet (Fig.2b). The crack path in the $\mathrm{Al}$ sheet also tended to followed flow lines in the weld nugget. This behaviour was more obvious in the galvanised steel welds where debris from the $\mathrm{Zn}$ coating were concentrated in bands, delineating flow lines formed by the tool during the welding process. 

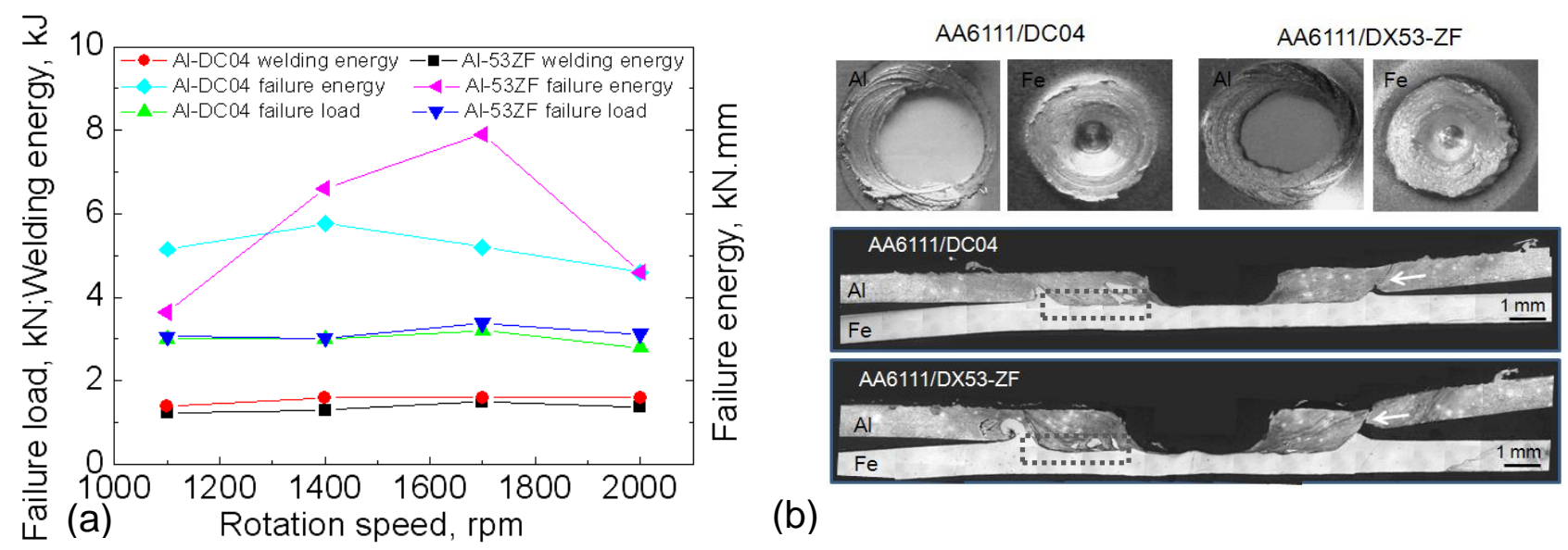

(b)

Fig. 2 Lap shear test results for the A1/DC04 and Al/DX53ZF welds showing; (a) the failure load and energy, as a function of rotation rate, as well as the welding energy, and (b) fractured samples produced with a rotation rate of $1700 \mathrm{rpm}$ showing a full nugget pull-out and cross sections from interrupted tests.

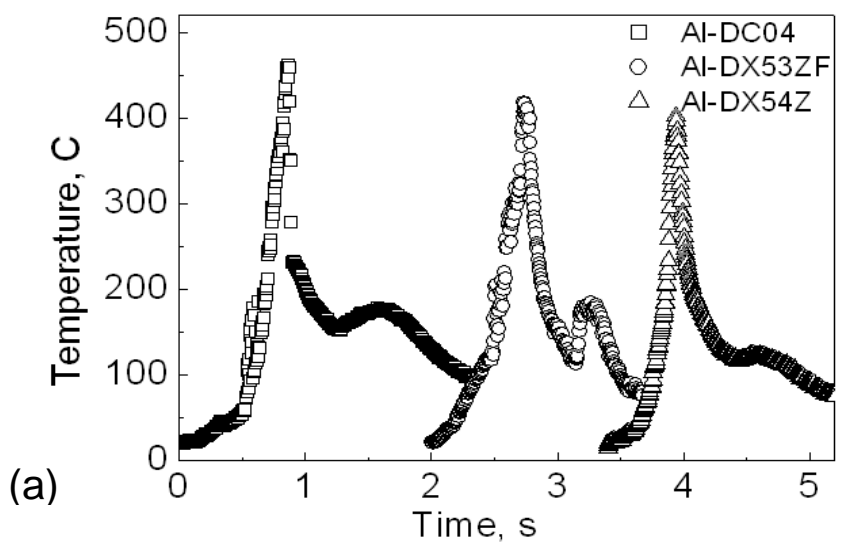

(b)
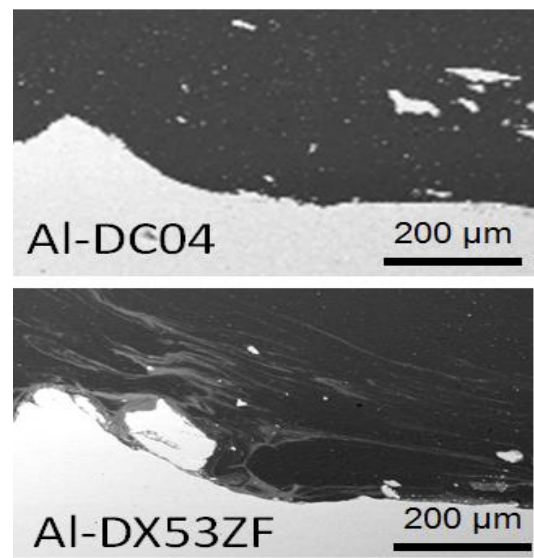

Fig. 3 (a) Weld cycle thermal histories (1700 rpm) measured for all three material combinations by thermocouples placed in the join line, (b) SEM- BSE images from the positions indicated in Fig.2b (dashed boxes), showing steel debris and dispersal of the hard Zn-Fe intermetallic galvannealed coating on the DX53-ZF steel sheet within the weld zones.

Effect of weld temperature. In Fig. 3 thermal histories are shown for all material combinations when welding at $1700 \mathrm{rpm}$, recorded using thermocouples placed in the join line as close as possible to the edge of the tool probe's path. Twin peaks can be seen in the thermal cycle. The first peak corresponds to when the outer edge of the probe passes close to the thermocouple, on its circular path, and the second lower peak arises when the probe moves to the weld centre to be extracted. The measurements will tend to underestimate the maximum weld temperatures because it is impossible to position the thermocouples immediately at the probe surface. Nevertheless, the highest peak temperature of $470{ }^{\circ} \mathrm{C}$ was recorded for the un-coated steel weld (AA6111/DC04) and lower values of 400 and $430{ }^{\circ} \mathrm{C}$ were measured for the soft zinc coated (AA6111/ DX54-Z) and galvannealed (AA6111/ DX53-ZF) steel joints, respectively.

In the weld produced with the soft galvanized steel (AA6111/ DX54-Z), it is notable that the peak temperature of $400{ }^{\circ} \mathrm{C}$ is higher than the eutectic reaction temperature between pure $\mathrm{Al}$ and $\mathrm{Zn}$ $\left(382{ }^{\circ} \mathrm{C}\right.$ [4]), which will readily lead to the formation of an interfacial liquid film during welding [2,3]. Liquation will cause slip between the $\mathrm{Al}$ and steel sheets, which will result in shear cracking in the weld zone and the subsequent freezing of expelled liquid accounts for the sticking problem encountered while retracting the FSSW tool. In comparison, the Fe-Zn intermetallic compounds in the galvannealed coat have considerably higher melting points than recorded (e.g. the lowest is for 
$\left.\mathrm{FeZn}_{13}=530{ }^{\circ} \mathrm{C}[4]\right)$ and despite a similar temperature being reached to in the AA6111/ DX54-Z welds, the thin $\mathrm{Zn}$ layer on the top of the coating would produce an insignificant volume of liquid.

Zn Dispersal. In the $\mathrm{Zn}$ coated steel welds bands of foreign material were visible, mixed into the aluminium weld zone (Fig. 3b). In Fig.3b it can be seen that the hard Zn-Fe intermetallic coating on the DX53-ZF steel sheet had been completely removed across the centre of the weld, where the base of the probe abraded the steel sheet. SEM and EDS analysis of the bands indicated that they contained a high $\mathrm{Zn}$ and Fe content and consisted of fine $0.1-0.5 \mu \mathrm{m}$ Fe- $\mathrm{Zn}$ rich particles, formed by the breakup of the brittle Fe-Zn intermetallic phases present in the galvannealed coating.

Interface structure. To develop a better understanding of the nature of the bond between the $\mathrm{Al}$ and steel sheets the welds' interface structures were characterised by TEM. In Fig.4 the thickness of the IMC reaction layers in welds produced with un-coated and galvannealed steel bottom sheets is plotted against rotation rate for a one second weld time weld. It can be seen that, except at $2000 \mathrm{rpm}$ with the Al/DC04 weld, the reaction layers increased in thickness with rotation rate and this is clearly related to the increasing temperature rise at the weld interface. The inset image for $2000 \mathrm{rpm}$ with the Al/DC04 sample shows that for this case the thicker IMC layer was broken up by the material flow during welding, which resulted in a thinner layer. The reaction layer was also considerably thinner for the galvannealed steel welds, where lower interface temperatures were recorded.
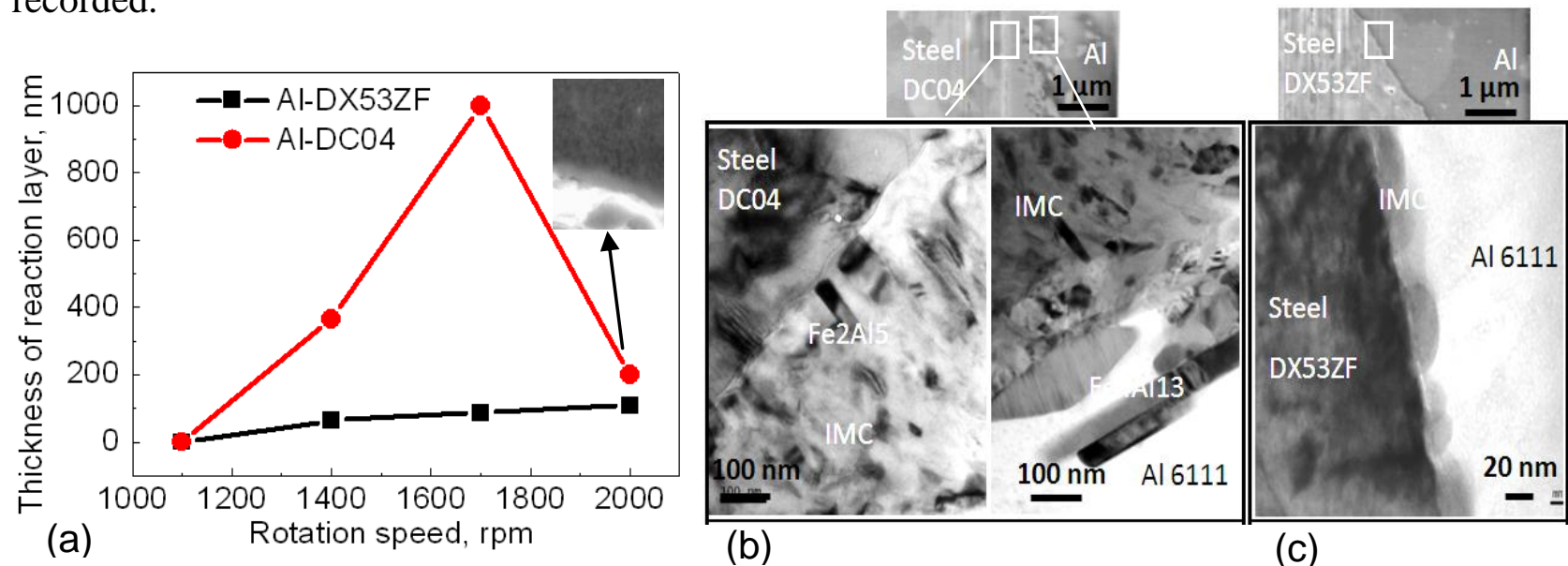

Fig. 4 (a) The thickness of the IMC layer plotted against rotation rate (rpm) for both Al/DC04 and Al/DX53ZF welds and TEM images comparing the IMC reaction layers seen at $1700 \mathrm{rpm}$ present in; (b) the AA6111/DC04 and (c) the AA6111/ DX53-ZF welds.

The maximum IMC layer thickness reached in the bare steel welds (at a $1700 \mathrm{rpm}$ rotation rate) was $1 \mu \mathrm{m}$, but was much thinner for the Al-galvannealed steel welds being only $60 \mathrm{~nm}$ thick. The interface structures of these two welds have been examined in more detail in Fig.4b. For this high energy welding condition, TEM showed that the thicker reaction layer present in the AA6111/DC04 welds was comprised of two Al-Fe compounds, that were identified by indexing selected area diffraction patterns and EDS chemical analysis, as $\mathrm{Fe}_{2} \mathrm{Al}_{5}$ and $\mathrm{FeAl}_{3}$ (also known as $\mathrm{Fe}_{4} \mathrm{Al}_{13}$ ). The $\mathrm{Fe}_{2} \mathrm{Al}_{5}$ phase formed a continuous layer, on the steel side of the weld and tended to grow directionally from the steel substrate with a fine columnar grain structure at a rate controlled by diffusion of $\mathrm{Al}$ through the IMC layer. This phase had a very fine grain size of $<50 \mathrm{~nm}$ wide by $200 \mathrm{~nm}$ long. In comparison, the $\mathrm{FeAl}_{3}$ phase tended to appear as discrete particles on the aluminium side of the IMC layer, and probably precipitated from the Al matrix when it became saturated with iron. With lower heat input /rpm welds (1400 rpm), when the IMC layer thickness reduced below $0.4 \mu \mathrm{m}$, only the $\mathrm{Fe}_{2} \mathrm{Al}_{5}$ phase was found and the layer became discontinuous and 
virtually disappeared for rotation rates below $800 \mathrm{rpm}$. TEM results for this condition have been previously reported in ref. [1].

In comparison, welds produced with the galvannealed coated steel with the same high tool rotation rate resulted in a much thinner 20-100 nm thick IMC reaction layer at the aluminium-steel interface. In this case, by using lattice imaging and fast Fourier transform patterns, the IMC layer was identified as being made up of only the $\mathrm{Fe}_{2} \mathrm{Al}_{5}$ phase. With the coated steel the galvanized coating was removed by the tool and dispersed into the aluminium stir zone, leaving a fresh bare steel surface, which might be expected to facilitate inter-diffusion and a more rapid intermetallic reaction. Enrichment of $\mathrm{Zn}$ was found at the joint interface and it is possible that the incorporation of $\mathrm{Zn}$ into the $\mathrm{Fe}_{2} \mathrm{Al}_{5}$ phase may affect its growth kinetics, particularly if $\mathrm{Zn}$ atoms occupy the vacant lattice sites [5]. However, it is difficult to separate such a chemical behaviour from the effect of the lower weld temperatures observed with the coated steels, for the same tool rotation rate, which would have a large influence on the reaction kinetics.

\section{Conclusions}

The effect of different galvanized surface coatings has been investigated on the viability of applying the ABC-FSSW process to joining $1 \mathrm{~mm}$ thick aluminium and steel sheets. With optimized conditions it has been demonstrated that high quality joints can be produced within a one second weld time between $\mathrm{Al}$ and galvannealed zinc steels, as well as with un-coated steel, using the ABC-FSSW approach. The joints have considerably higher weld strengths and fracture energies than have previously been achieved by any conventional FSSW process, over a wide process window, and exhibit a full nugget pull-out failure mode. In contrast, the soft zinc coated steel to Al combination proved to be unweldable by ABC-FSSW due to liquation at the interface.

Investigation of the joint interface IMC reaction layers revealed that with un-coated steel in the worst case it was still less than $1 \mu \mathrm{m}$ thick, but could be reduced to an insignificant level by control of the heat input. In comparison, with the galvannealed steel the maximum IMC layer thickness was less than $100 \mathrm{~nm}$, and this difference can be attributed to the reduced peak welding temperature. TEM has shown that thicker reaction layers were comprised of a mixture of $\mathrm{Fe}_{2} \mathrm{Al}_{5}$ and $\mathrm{FeAl}_{3}$ phases, whereas thinner layers contained only the $\mathrm{Fe}_{2} \mathrm{Al}_{5}$ phase.

\section{Acknowledgement}

The authors wish to thank the EPSRC for funding this research through; LATEST2 (EP/G022402/1). We are also grateful to N. Wright \& M. Shergold, (Jaguar Land Rover Group) and A Smith (Corus) and T. Burman (Novelis) for provision of materials.

\section{References}

[1]. Y.C. Chen, A. Gholinia and P.B. Prangnell, Interface structure and bonding in abrasion circle friction stir spot welding - a novel approach for rapid welding aluminium alloy to steel automotive sheet. Mater. Chem. Phys. 134 (2012) 459- 463.

[2] R. S. Mishra, M. W. Mahoney, Friction stir welding and processing, ASM International, 2007.

[3] P.B. Prangnell, Y. C Chen, A. Panteli, F. Haddadi, Friction spot welding dissimilar materials with rapid cycle times, THERMEC' 2011, Quebec City Convention Centre, August 1-5, 2011.

[4] A.R. Marder, The metallurgy of zinc-coated steel, Progress in Mater. Sci. 45 (2000) 191-271.

[5] J. Nakano, D.V. Malakhov, S. Yamaguchi, G.R. Purdy, A full thermodynamic optimization of the $\mathrm{Fe}-\mathrm{Zn}-\mathrm{Al}$ system within the $420-500{ }^{\circ} \mathrm{C}$ temperature range. Calphad 31 (2007) 125-140. 